\title{
Glutamine supplements in the critically ill
}

\author{
Raymond D'Souza MRCP Jeremy Powell-Tuck MD FRCP
}

J R Soc Med 2004; 97:425-427

Glutamine is a five-carbon neutral aminoacid containing two carboxyl groups one of which is bound to nitrogen, forming an amide group. It is the most abundant free aminoacid in the body. ${ }^{1}$ In the extracellular fluid it constitutes about $25 \%$ of the free aminoacid pool, in skeletal muscle more than $60 \% .^{1}$ A healthy $70 \mathrm{~kg}$ man contains $80 \mathrm{~g}$ of glutamine and the concentration of glutamine in his blood is 500 $700 \mu \mathrm{mol} / \mathrm{L}$.

Glutamine has numerous functions in normal physiology-for example, it acts as a precursor for protein synthesis; it provides the nitrogen for synthesis of arginine, purines, pyrimidines, nucleotides, glutathione and taurine (the last two being important antioxidants); and it transports amino-nitrogen to intestine, liver and kidney. ${ }^{1-3}$ With its involvement in renal ammoniagenesis it plays a key role in acid-base homoeostasis. ${ }^{2}$ Particularly reliant on glutamine as a fuel are the rapidly dividing cells of the gastrointestinal tract (enterocytes, colonocytes) and the immune system (lymphocytes, macrophages). ${ }^{3,4}$ Glutamine may affect stress-induced accumulation of extracellular fluid by changing the cellular hydration state. ${ }^{4}$ An increase in cellular hydration acts as an anabolic proliferative signal, whereas cell shrinkage is catabolic and anti-proliferative.

Under normal circumstances glutamine is readily synthesized and stored in skeletal muscle whilst lesser amounts are produced in the liver, lungs and brain. ${ }^{1}$ Since it can be produced by the body it is regarded as a nonessential aminoacid. However, this does not apply to conditions of excessive organ/tissue demand such as sepsis and other states of catabolic stress declines greatly. ${ }^{4}$ In these circumstances, production of glutamine in the body is insufficient to meet the increased requirement by the gut, immune system, liver and kidneys. ${ }^{4}$ The demands are then met in part by protein breakdown in skeletal muscle, with release of large amounts of glutamine and glutamine becomes a conditionally essential aminoacid.

Department of Human Nutrition, Queen Mary's School of Medicine and Dentistry, Barts and The London NHS Trust, London, UK

Correspondence to: Raymond D'Souza, Digestive Disease Research Centre, Queen Mary's School of Medicine and Dentistry, Barts and The London NHS Trust, Whitechapel, London E1 1BB, UK

E-mail: raymonddsou@yahoo.com

\section{CONSEQUENCES OF GLUTAMINE DEPLETION}

Glutamine is a major fuel and nucleotide substrate in both enterocytes and the gut associated immune system. ${ }^{3}$ During critical illness the gut mucosal cells, deprived of glutamine, cease to perform their barrier function and allow entry of luminal toxins and bacteria directly into the portal bloodstream (bacterial translocation syndrome). ${ }^{3}$ Conventional total parenteral nutrition (TPN), which is glutaminefree, can actually worsen mucosal permeability. The body then breaks down muscle protein to release glutamine and aminoacids for the gut and immune system.

\section{LIMITATIONS TO USE OF FREE GLUTAMINE}

In theory, the intracellular glutamine depletion caused by hypercatabolic states should be treatable by glutamine replacement, so maintaining muscle protein. However, the limited solubility $\left(3 \mathrm{~g} / \mathrm{dL}\right.$ at $\left.20^{\circ} \mathrm{C}\right)$ and instability of free glutamine hamper its use for this purpose. ${ }^{5}$ The rate of breakdown depends on temperature, $\mathrm{pH}$ and anion concentration. Free glutamine can be provided by adding the crystalline aminoacid to a commercially available aminoacid solution before administration, but this is timeconsuming. ${ }^{5}$

The drawback of glutamine instability can, however, be overcome by use of synthetic dipeptides. ${ }^{6,7}$ Dipeptides with glutamine residues at the $\mathrm{C}$-terminal position are highly soluble in water and are reasonably stable during heat sterilization and storage. 6,7 Two preparations now available for addition to parenteral nutrition are L-alanyl-L-glutamine (Ala-Gln) and glycyl-L-glutamine. These intravenous preparations seem free from side-effects and the infused peptide is quickly hydrolysed.6,7 Supplementation with glutamine or glutamine-containing dipeptides improves nitrogen balance and maintains the intracellular glutamine pool, though the doses required are much higher than the standard daily oral intake of around $5 \mathrm{~g} \cdot{ }^{6}$

\section{CLINICAL STUDIES}

Much of the information on glutamine supplemented nutrition comes from work in laboratory animals in which glutamine enriched parenteral or enteral nutrition was compared with isonitrogenous isocaloric glutamine-free nutrition. This work leaves no doubt that either enteral or parenteral provision of glutamine dipeptides can maintain 
the intracellular or extracellular glutamine pool. ${ }^{8}$ Parenteral dipeptide nutrition promotes growth and nitrogen retention and there is less muscle loss during stress. ${ }^{8}$ Glutamine replacement preserves intestinal structure and function and improves bowel mucosal repair following chemotherapy, irradiation and sepsis. During chemotherapy and sepsis, glutamine supplementation decreases bacteraemia and maintains tissue glutathione levels. ${ }^{9}$ Glutamine lessens pancreatic atrophy and hepatic steatosis associated with TPN or elemental enteral diets. ${ }^{9}$

\section{Glutamine-supplemented enteral feeding}

Where there is a choice, enteral feeding is preferable to parenteral. In the critically ill patient on the intensive-care unit, parenteral nutrition is used only when enteral feeding is unsuccessful or impractical. Conventional enteral feeds provide some glutamine (protein-based enteral products 6-8 g/day, and peptide-based products $1-5 \mathrm{~g} /$ day), but this is insufficient for the critically ill patient and some workers argue for supplements of $10-20 \mathrm{~g} /$ day. ${ }^{10} 50-80 \%$ of free glutamine is absorbed by the gut during routine enteral feeding and plasma glutamine can be seen to rise with supplementation. Supplemented enteral feeds can reverse the changes in intestinal permeability associated with parenteral feeds, possibly by yielding a high glutamine concentration $(>2.5 \mathrm{mmol} / \mathrm{L})$ in the gut lumen. ${ }^{11-13}$ Some researchers find that addition of glutamine to enteral nutrition formulas in critically ill patients reduces rates of pneumonia, sepsis and bacteraemia, with shortened hospital stays and lower hospital costs, ${ }^{11-14}$ but others report no benefit. $^{15}$ In a systematic review of work on enteral glutamine, Novak et al. ${ }^{16}$ reach negative conclusions - no reduction in mortality, complications or hospital stay.

Perhaps one reason for this disappointing result is that high doses of enteral glutamine are difficult to give, particularly during the early course of the illness. In the work on parenteral glutamine, high doses were seen to be more effective than low doses. One way to provide high concentrations would be to give the glutamine intravenously, separately from the enteral feed. ${ }^{17}$ In lowbirthweight babies the evidence on enteral glutamine is more secure: it reduces morbidity, lessening the incidence of sepsis. ${ }^{18}$

\section{Glutamine-supplemented parenteral feeding}

The first clinical study with a synthetic dipeptide was performed in 1989 in patients undergoing elective resection of the colon or rectum. ${ }^{19}$ An improvement in net nitrogen balance in the glutamine-replacement TPN subgroup was associated with maintenance of the intracellular glutamine pool. ${ }^{17}$ In surgical patients, TPN supplemented with Gly-Gln improved nitrogen economy, had an immunostimulatory
Box 1 Patient groups that may benefit from glutamine supplementation (modified from Ref. 25)

Severe catabolic illness
Burns, multiple trauma
Bone marrow transplantation
Acute/chronic infection
Other critical illness
Intestinal dysfunction
Inflammatory bowel disease
Infectious enteritis
Necrotizing enterocolitis or intestinal immaturity
Short-bowel syndrome
Mucosal damage following chemotherapy, radiation, or critical
disease
Surgical gastrointestinal patients
Immunodeficiency syndromes
Immune system dysfunction associated with critical illness or
bone marrow transplantation
Acquired immunodeficiency syndrome
Advanced malignant disease
Glutamine-depleted patients with cancer cachexia
Low-birthweight babies

effect on lymphocytes, maintained plasma glutamine concentration and shortened hospital stay. ${ }^{19,20}$

Since then, glutamine-enriched TPN has been found beneficial in several conditions. ${ }^{19-25}$ It can help to maintain the structure and function of the small bowel in inflammatory bowel disease or neoplastic disease and thus reduce bacterial translocation, ${ }^{3}$ and improves weight gain, reduces hospital stay and lessens the risk of nosocomial infections in patients undergoing bone marrow transplantation. ${ }^{22}$ After bone marrow transplantation the treatment has been associated with increased percentages of lymphocytes and improved markers of $\mathrm{T}$-cell function together with a degree of hepatic protection, possibly due to its effects on tissue glutathione concentrations; ${ }^{22}$ moreover, glutaminesupplemented patients showed advantages in psychosocial wellbeing, whether through some direct action in the brain or through its effects on protein status. Intravenous glutamine supplementation in severely burned patients reduced Gram-negative bacteraemia, with a trend towards lower mortality. ${ }^{23}$ In meta-analysis, Novak et al. ${ }^{16}$ combined two large studies of critically ill patients ${ }^{21,23}$ who had gastrointestinal failure. Their conclusion was that, after six days of infusion, glutamine-supplemented patients had a moderately (but significantly) lower mortality rate than the non-supplemented. They also concluded that a glutamine dose higher than $0.20 \mathrm{~g} / \mathrm{kg}$ per day has a greater effect than a lower dose. ${ }^{16}$ Like enteral glutamine, parenteral supplementation is beneficial in low-birthweight babies, in whom it reduces sepsis, lessens time on the ventilator and speeds the change to enteral feeds. ${ }^{24}$ 


\section{CONCLUSIONS}

A decade ago, Ziegler et al. ${ }^{26}$ indicated the potential applications of glutamine suplementation, and many of their predictions have been borne out. Box 1 represents our update of their proposals. In enteral feeds, glutamine supplementation has not yielded clear benefit. One reason may be the difficulty of administering high doses, especially during the early course of the illness. Enteral glutamine has, however, shown itself useful in low-birthweight babies, reducing sepsis and mortality.

With parenteral glutamine, the patients most likely to benefit are the critically ill and those at high risk of gut dysfunction. In such patients, a dose of 15-25 g per day may be sufficient. Like enteral glutamine it is beneficial in low-birthweight babies, reducing sepsis and time on the ventilator. The availability of stable preparations of glutamine dipeptide opens the way to better management of the subgroups of patients most at risk.

\section{REFERENCES}

1 Young V, Ajami A. Glutamine: the emperor or his clothes? J Nutr 2001;131(suppl):2449-59S

2 Lacey JM, Wilmore DW. Is glutamine a conditionally essential amino acid? Nut Rev 1990;48:297-309

3 Ziegler T, Bazargan N, Leader L, et al. Glutamine and the gastrointestinal tract. Curr Opin Clin Nutr Metab Care 2000;3:35562

4 Newsholme P. Why is L-glutamine metabolism important to cells of the immune system in health, postinjury, surgery or infection? J Nut 2001;131(suppl):2515-22S

5 Melis G, ter Wengal N, Boelens PG, van Leeuwen PA. Glutamine: recent developments in research on the clinical significance of glutamine. Curr Opin Clin Nutr Metab Care 2004; 7:59-70

6 Matthews D, Battwzzati A, Furst P. Alanylglutamine kinetics in humans. Clin Nutr 1993;12:57

7 Brandl M, Sailer D, Langer K, et al. Parenteral nutrition with an amino acid solution containing a mixture of dipeptides in man. Contr Infusion Ther Clin Nutr 1987; 17:103

8 Stehle P, Ratz I, Furst P. In vivo utilisation of intravenously supplied L-alanyl-L-glutamine in various tissues of the rat. Nutrition 1989;5:411

9 Karner J, Roth E, Ollenschlager G, et al. Glutamine containing dipeptides as infusion substrates in the septic state. Surgery 1989;106:893
10 Kuhn K, Stehle P, Furst P. Glutamine content of protein and peptidebased enteral products. J Parent Ent Nutr 1996;20:292-5

11 Houdijk A, Rijnsburger E, Jansen J, et al. Randomised trial of glutamine-enriched enteral nutrition on infectious morbidity in patients with multiple trauma. Lancet 1998;352:772-6

12 Jones C, Palmer A, Griffiths R. A randomised clinical outcome study of critically ill patients given glutamine-supplemented enteral nutrition. Nutrition 1999; 15:108-15

13 Beier-Holgerson R, Boesby S. Influence of postoperative enteral nutrition on post-surgical infections. Gut 1996;39:833-5

14 Garrel D, Patenaude J, Nedelec B, et al. Decreased mortality and infectious morbidity in adult burn patients given enteral glutamine: a prospective, controlled, randomized clinical trial. Crit Care Med 2003; $31: 2444-9$

15 Hall JC, Dobb G, Hall J, et al. A prospective randomised trial of enteral glutamine in critical illness. Intens Care Med 2003;29:1710-16

16 Novak F, Heyland DK, Avenell A, Drover JW, Su X. Glutamine supplementation in serious illness: a systemic review of the evidence. Crit Care Med 2002;30:2002-29

17 Wischmeyer P, Lynch J, Liedel J, et al. Glutamine administration reduces Gram-negative bacteraemia in severely burned patients: a prospective, randomised, double-blind trial versus isonitrogenous control. Crit Care Med 2001;29:2075-80

18 Neu J, Roig J, Meetze W, et al. Enteral glutamine supplementation for very low birth weight infants decreases morbidity. $J$ Pediatr 1997; 131:691-9

19 Stehle P, Zander J, Mertes N, et al. Effect of parenteral glutamine peptide supplements on muscle glutamine loss and nitrogen balance after major surgery. Lancet $1989 ; \mathbf{i}: 231$

20 Pastores SM, Kvetan V, Katz D. Immunomodulatory effects and therapeutic potential of glutamine in the critically ill surgical patient. Nutrition 1994;10:385

21 Powell-Tuck J, Jamieson C, Bettany G, et al. A double blind, randomised, controlled trial of glutamine supplementation in parenteral nutrition. Gut 1999;45:82-8

22 Ziegler T, Young L, Benfell K, et al. Clinical and metabolic efficacy of glutamine-supplemented parenteral nutrition after bone marrow transplantation. A randomized, double-blind, controlled study. Ann Intern Med 1992;116:821

23 Griffiths R, Jones C, Palmer T. Six-month outcome of critically ill patients given glutamine-supplemented parenteral nutrition. Nutrition 1997; 13:295-302

24 Goeters C, Wenn A, Mertes N, et al. Parenteral l-alanyl-L-glutamine improves 6-month outcome in critically ill patients. Crit Care Med 2002;30:2032-7

25 Lacey J, Crouch J, Benfell K, et al. The effects of glutaminesupplemented parenteral nutrition in premature infants. J Parent Ent Nutr 1996;20:74

26 Ziegler $\mathrm{T}$, Smith $\mathrm{R}$, Byrne $\mathrm{T}$, et al. Potential role of glutamine supplementation in nutrition support. Clin Nutr 1993;12:S82 